Volume and Issues Obtainable at Center for Sustainability Research and Consultancy
Journal of Business and Social Review in Emerging Economies
ISSN: 2519-089X (E): 2519-0326
Volume 6: No. 3, 2020
JSRᄃ
Journal homepage: www.publishing.globalcsrc.org/jbsee

\title{
Do Print Media Cater the Needs of Society? A Study to Analyze the Coverage of Health Issues in Major Dailies of Pakistan
}

\author{
${ }^{1}$ Imran Muslim, ${ }^{2}$ Muhammad Ahsan Bhatti, ${ }^{3}$ Tahir Mahmood \\ ${ }^{1}$ Assistant Professor, Department of Mass Communication Government College University Faisalabad, Punjab, \\ Pakistan, imranmuslim@gcuf.edu.pk \\ ${ }^{2 \& 3}$ Assistant Professor, Department of Communication Studies Bahauddin Zakariya University, Multan, Pakistan, \\ Ahsanbhatti@bzu.edu.pk, Tahir_rule@bzu.edu.pk

\begin{tabular}{l}
\hline ARTICLE DETAILS \\
\hline History \\
Revised format: August 2020 \\
Available Online: September \\
2020
\end{tabular}

\section{Keywords} \\ Health Issues, Print media, \\ Content Analysis

\section{JEL Classification} \\ $M 1, M 1$

\section{ABSTRACT} \\ This research study is conducted to identify the contribution of print media \\ in highlighting the health specific information for their readers. A content \\ analysis was made for five major Urdu and English dailies, to understand \\ the importance given to health issues in terms of space given, frequency and \\ tone of the contents. The findings of study concluded that mostly articles \\ discussed the health education, specific diseases were less reported. Mostly \\ articles were in neutral and positive tone respectively. Almost one fourth of \\ the articles presented the multiple viewpoints with conclusion as elaborated \\ multiple aspects such as diagnosis, precautionary measures, treatments and \\ remedies/suggestions. Two-thirds of the articles discussed the non-scientific \\ evidence. It was conclude that Information related to health was treated very \\ casually and no serious and result oriented effort was made by the print \\ media.
}

\section{OPEN ACCESS}

(C) 2020 Center for Sustainability Research and Consultancy Pakistan under a Creative Commons Attribution-NonCommercial-ShareAlike 4.0

Corresponding author's email address: Ahsanbhatti@bzu.edu.pk

Recommended citation: Imran, M., Muhammad A. B., \& Tahir, M. (2020). Do Print Media Cater the Needs of Society? A Study to Analyze the Coverage of Health Issues in Major Dailies of Pakistan. Journal of Business and Social Review in Emerging Economies, 6(3), 991-998

\section{Introduction}

Experiencing good health is always noteworthy not only for people but also for the development of the country. Mass media is one of those options from which people expect to highlight their issues. It's a general perception that Mass media, specially the print media, gives more attention to the political affairs and ignore the social issues of the society. People look forward towards a better treatment with the issues of their life especially the health related information. Gupta and Sinha (2010) state that the demand for accurate, relevant and timely health information by the population is stronger. The Public health community relies on the media for help, attention and authentication. It is considered as a major source of information on health and science. A study by the Pew Research Center in 2008 mentioned the important role played by the media in society. They point out that millions of Americans are turning daily to various media to get information, and what people learned make them more clear which issues get more or less worth in public agenda. When general health conditions are at stake, news media conduct various seminars and awareness programs to convey important message that's urgent to deliver among people as best example regard that is anti-dengue campaign conducted by newspapers. Therefore, in this way they function as a integral part in promoting awareness 
about health. Role of media make the media organization satisfied that they are going their duty well. Because of that it's becoming trendy that people rely on media information heavily. For people generally the media could be the enough worthy source of information about health but health information in the media cannot replace a personal medical opinion. It is necessary for people to understand (Schwitzer et al.).

Health news has been shown to be a source of understanding for some health problems and to influence their judgments about adopting any health behavior and activity. Dutta-Bergman (2004) analyzed search of individuals for news related to health problems and how new media become a platform where people come across to consult for enhancing information about health issues news and find consultation about information they already have it. Similarly individuals seek health related information from other mainstream media and interpersonal communication if they have strong beliefs about health. On the other hand, news media such as newspapers are least consuming source of information for less motivated individuals about their health and fitness.

Health-related topics that are getting covered in newspaper contained in the news affects the people perception about various health problems not only on individual level but also on individual level and ultimately they construct their beliefs, knowledge health behaviors accordingly. The previous study also explains that the media set up a program for the public by choosing to focus on specific health problems and to reduce other problems (McCombs and Shaw, 1972). In addition, research on news articles on health explains that sensational stories have helped to raise the awareness among people. Newspapers frame the understanding of people about health disparities using various frameworks. Media representatives on health issues affect public perception of these issues (Patterson, 2015). Kitzinger (2004) states that the development of agendas and coaching processes helps to address known public issues and attitudes toward these issues. He noted that public attention on the issue has been correlated with media attention on the issue. Kahneman and Tversky (1984) stated that the media framework has been shown to impact evaluator evaluation and decision making. Diedong (2013) states that the media can influence the public with appropriate information to enable them to build healthy behave and attitudes to attain their health better.

The print media as a source of information is the noteworthy in contemporary society. Though a lot of people have approach to a network of sharing information interpersonally, the news media always remains a critical component in acquiring the knowledge, , especially on the far side of the direct experience of people Luhmann and Cross (2000). In this way relationship between readers and news content become stronger and that enable to create a direct media impact on people (Tsfati \& Cappella,2003). Health as a most important part of life for every person is always a common concern. Today, people are more interested in information about diseases, preventative measures, medications and health-promoting factors.

Well informative, educational and warned about the disease is the positive aspect of the news media (Berry, Wharf, Higgins, and Naylor, 2007) while sensational, health problems and cause unnecessary threats (Signorelli, 1993) or expectations (Buntin, Jain, \& Blumenthal, 2010) can have a negative impact on the public. Not only they found the importance of the accuracy of health related information in the media, but also poor information on health issues can lead to mistrust in communication between patient and doctor. The media gives a vital source of information that is related to health problems, with estimated $80 \%$ of people have reliance on news media (newspapers, magazines, television) for health related information, its larger percentage from those who consult physicians and doctors (Covello \&Peters, 2002). health campaign of media has been one of the effective way of reduction, or to prevent an increase of diseases such as AIDS, leprosy SARS, and preventable diseases by children as indicated in Uganda, Thailand, India, Pakistan, Nepal, Brazil and Honduras,. Instead, Signorelli (1993) claimed that the media was guided by what was sold. In health domain, it is sensational hype that sells. He described the hype of health as a health related new that overemphasize and entertaining. Health assumptions have the potential to disrupt society's health. People often collect information about health related news and follow-up reports with a improved details (Brodie, Hamel, Altman, ParkBlendon \& Benson, 2003). Despite the effort to provide a variety of perspectives and the results are not consistent to describe the picture more complete and inform the public better. There is also very concerning that news articles that provide two-sided information generate uncertainty and state of dissatisfaction (Clarke \& Everest , 2006). Previous studies have analyzed that public will only approach health related news if they believe that information provided by news will tell them the way to improve their health condition (Cooper, Burgoon, Roter, 
2001).Health related news that do not contain healthy information can confuse the public, causing scare and anxiety, without enhancing productivity (Chang, 2012a).

Health news sometimes produce doubtful information about health-related behaviors, which can put the people in a dilemma of complying or disobeying. This dilemma is particularly related to food and nutrition news, which may leave the public wondering whether they should enhance the consumption of certain foods or not (Angell and Kasirer, 1994). News coverage causes anxiety or scare that high can also bring down people's encouragement to deal with news, while fears arouse the defensive avoidance (Witte, 1994) and bring down public working out on advocated health problems (Hale, Lemieux and Mongeau, 1995).

In the latest study that compares news media as a medium of providing information about health. Dutta-Bergman (2004) found that the common use of active channels (print media such as newspapers, magazines and Internet) are the primary source of public-oriented health, whereas common use of "passive channel (radio and television) are source for those who are less concerning about the health issues. As it is distributed in newspapers and magazines, Articles that publish in the print media have potential to influence the thoughts of people due to the reproducibility (access available during proof reading or visual scanning ), details and profoundness (newspaper capacity to provide complex and detailed content), scheduling (potential for enhancing priority issues - important issues) and reliability. The newspaper plays an important role in spreading knowledge about various aspects of community-related information. Almost all popular newspapers publish educational articles on various topics such as health, including nutrition, legal issues, science, business, fashion, women's issues, careers, and so on. The newspapers is a vital source of health and nutrition information for many readers. The leading newspapers conduct health forum that provide exclusive columns where experts provide answers to individual reader questions on the topic above. These answers also serve as a solution for many readers facing similar problems. The news media provide education and important awareness about health issues. It effectively educates the people about up-to-date about health and fitness related information, not only educating but also have significant impact on thinking and making health-related decisions (AbuSabha, 1998).

Collins, Abelson, Pyman and Lavis ( 2006) noted that Newspaper is acknowledged as an important source of health related information and means of public policy important source of information and a means of public policy to convince people's opinions based selection and delivery of health issues. National survey conducted by Kaiser foundation also confirms that news media in America is one of the influential source of delivering information for people about HIV- Americans have more often reliance on news media than experts, health care providers or schools (Kaiser foundation, 2004). Most researchers believe that the media is a valuable tool for disseminating HIV information (Doak et al., 1998).

\section{Purpose of the Study}

The purpose of this research is systemize analysis of the major daily newspapers named as; Daily Pakistan Times, Daily Dawn, Daily Express, Daily Dunya and Daily Nawai-e-Waqt covering the areas of human development, specially the health issues. This study covered the time span of one Year, i.e. July, 2018 to June, 2019. Many studies have seen a closer coverage of information on some health issues such as breast, cervical and skin cancers and second hand smoking with others. This research work examined the broader health coverage, as reported in these five papers, to determine how and why health as a public issue receives attention and treatment. Using the agenda setting, this study examined whether with coverage and importance given to the health news, which was last raised or less covered compared to other topics. This study examines what is read in health news, resources and frameworks. Therefore, the purpose is to yield practical indication of newspapers' contribution to educate and aware among the public about health and well-being.

The purpose of research is also to examine the content quantity and content structure presented in health related news articles. Health news is to be verified in terms of message source, tone, narration and views presentation.

\section{Objectives of Research}


The Broad objective of study is to analyze the construction of health news in the print media both quantitatively and qualitatively, with a focus on the reach of the print media in 2018 and 2019 by adopting the "health care" approach. Specific objectives of this research were following:

- To know the categories or types of health problems treated

- To evaluate which health topics are most covered in health-related articles

\section{Research Questions}

- How many articles of Newspapers focus on health-related issues?

- What are the specific health issues that are being addressed?

- What kind of tone health news articles have?

\section{Methdology}

Content analysis as a systematic method select the content that is to be analyzed is according to the precise and consistent rules put in for with all the content considered to be treated in the same way. Objectivity means that the analysis has no bias so that the researchers will produce the same results if the study is taken up by another researcher (Wimmer \& Dominick, 2011).

This study examined the major Urdu and English newspapers in Pakistan. Daily newspapers distributed throughout the country are selected for this analysis: Daily Pakistan Times, Daily Dawn, The Daily Express, Daily Dunya and Daily Nawai-e-Waqt. At the time of data collection, the newspapers which were selected to be analyzed in this study were considered as top circulated newspapers across the country, for this study. Reason to of selecting these five sampled newspapers were given below: (a) these articles are one of the main articles circulating on their local market and (b) each newspaper has an accessible digital archive.

The universe of this study consists of all the articles published in the editions of magazines with health content within one years. Like the study by Bonaire (2012), which used the US health content in the journal, the two-week report on health articles was verified and 858 articles were used in this analysis. Therefore, this study was conducted using stories spanning a period of one year.

\section{Unit of Analysis}

An individual article that related to health was unit of analysis in this study. Health news articles were defined a article that in health editions that covered the topics such as: diseases such as hypertension, diabetes, cancer, kidney disease; the provision of health facilities and health insurance issues; health policy; issues related to pharmaceuticals; Drug recall; side effects of medicines; environmental hazards effecting to health; malnutrition; unsafe practices; risk factors about health; scientific and medical advancement; health infrastructure; benefit factor ; public health / education and health promotion; asked for support for the treatment of certain diseases; training of health professionals and risks to public health and stories that are not included in this category and are classified as "other".

\section{Coding}

Wimmer and Dominick (2011) explained that coding involves in placing the unit of analysis in content categories. They further describe about two methods for defining a content categories named as emerging coding and prior coding. Emerging coding construct the categories after initial data checks whereas Priori category is established before data is collected (Wimmer and Dominick, 2011). This study practiced the emerging coding. The provision of coding guide additional the coding sheet produces a consistent coding framework that reduces the potential for subjective judgments. Small adjustments have been made to the codes and guides to improve their specificity. At the beginning of each article coded by identifying of name of the paper: (1)Pakistan Times , (2) Daily Dawn, (3) Daily Express, (4) Daily Duniya, and (5) Day Nawai-e-Waqt. In addition, to measure the amount of space given to the health new articles every article has coded column-length accordingly. Next, every article was coded for the variables (Scientific and medical 
advancement, Public health policy, Health education and fund raising, Health infrastructure. Next, in health news articles tone was coded as negative, positive, mixed and neutral in order to analyze the framework that was practiced in health news articles. Next number of presented viewpoints was codes as single viewpoints, multiple viewpoints with conclusion or multiple viewpoints without conclusion. Another group of coded variables was the cited or collected through source of information, namely: researchers, health professionals, government officials, support groups, nonexperts and unidentified experts. In order to examine the utilizing of the framing in articles, the narration of content was coded by the reporting method exercised to display information about health related issues with frames such as Factual narration, Subjective narration, both factual and subjective narration and Hypothetical narration.

\section{Findings}

\section{General Health Topics}

Table 1: General Health Topics covered by Newspapers

\begin{tabular}{lccccc}
\hline \multirow{2}{*}{ Newspaper Id } & \multicolumn{5}{c}{ Type of Health Topic } \\
\cline { 2 - 5 } & Public health policy & Scientific/medical Advancement & Health infrastructure & Health Education & Total \\
\hline Pakistan Times & 12 & 1 & 19 & 15 & 47 \\
Daily Dawn & 4 & 13 & 11 & 27 & 55 \\
Daily Duniya & 2 & 34 & 2 & 63 & 101 \\
Daily Express & 3 & 12 & 5 & 15 & 35 \\
Nawai-e-Waqt & 0 & 2 & 23 & 5 & 30 \\
Total & 21 & 62 & 60 & 125 & 268 \\
\hline
\end{tabular}

In coverage of general health topics, most frequently covered topic was about health education (125 articles, 14.56 $\%)$. Second most covered topic in article was medical and scientific advancements (62 articles, 7.22\%), followed by health infrastructure (60 articles, 6.99\%) and public health policy (21articles, $2.44 \%$ ).

Most articles were found to had Factual Narration (119 articles, 44.56\%), followed by subjective Narration (72 article 26.96\%) and Both Factual and Subjective Narration (63 articles, 23.59\%). Articles with Hypothetical Narration had least covered (13 articles 4.86\%).

\subsection{Diseases}

In health related news articles, in term of coverage of diseases, Infectious Diseases was the mostly covered disease (43 articles, 6.01\%) followed by heart diseases (33 Articles 3.84\%) being the second most covered disease. Following those two diseases, Diabetes and Cancer were covered $3.72 \%$ (32 articles) and $2.21 \%$ (19 articles).

Table 2: Diseases specific coverage by the Newspapers

\begin{tabular}{|c|c|c|c|c|c|c|}
\hline \multirow{2}{*}{ Type of Diseases } & \multicolumn{5}{|l|}{ Newspaper Id } & \multirow{2}{*}{ Tota } \\
\hline & Pakistan Times & Daily Dawn & Daily Duniya & Daily Express & Nawai-e-Waqt & \\
\hline Mental Illness & 2 & 3 & 1 & 1 & 6 & 13 \\
\hline Cancer & 4 & 6 & 2 & 0 & 7 & 19 \\
\hline Heart Disease & 6 & 9 & 10 & 2 & 6 & 33 \\
\hline Hepatitis & 1 & 1 & 2 & 0 & 5 & 9 \\
\hline Infectious Diseases & 13 & 17 & 4 & 3 & 6 & 43 \\
\hline Eye Disease & 1 & 0 & 0 & 0 & 5 & 6 \\
\hline Arthritis and osteoporosis & 3 & 5 & 1 & 2 & 5 & 16 \\
\hline Diabetes & 6 & 13 & 4 & 3 & 6 & 32 \\
\hline Epilepsy & 4 & 0 & 0 & 0 & 3 & 7 \\
\hline ENT & 3 & 4 & 1 & 0 & 5 & 13 \\
\hline Kidney & 0 & 2 & 0 & 0 & 8 & 10 \\
\hline Paralysis & 0 & 1 & 1 & 0 & 0 & 2 \\
\hline Thalassemia & 0 & 0 & 1 & 1 & 1 & 3 \\
\hline HIV/AIDS & 1 & 5 & 2 & 2 & 5 & 15 \\
\hline Reproductive Related & 1 & 2 & 2 & 2 & 3 & 10 \\
\hline Digestive system & 1 & 3 & 2 & 1 & 3 & 10 \\
\hline Other Diseases & 0 & 1 & 3 & 2 & 4 & 10 \\
\hline Total & 46 & 72 & 36 & 19 & 78 & 251 \\
\hline
\end{tabular}




\begin{tabular}{|c|c|c|c|c|c|c|}
\hline \multirow[b]{2}{*}{ Type of Diseases } & \multicolumn{4}{|c|}{ Framing of Diseases } & \multirow[b]{2}{*}{10.00} & \multirow[b]{2}{*}{ Total } \\
\hline & $\begin{array}{l}\text { Factual } \\
\text { Narration }\end{array}$ & $\begin{array}{l}\text { Subjective } \\
\text { Narration }\end{array}$ & $\begin{array}{l}\text { Both Factual and } \\
\text { Narration }\end{array}$ & $\begin{array}{cl}\text { Subjective } & \text { Hypothetical } \\
& \text { Narration }\end{array}$ & & \\
\hline Heart Disease & 7 & 5 & 1 & 0 & 0 & 13 \\
\hline Cancer & 11 & 4 & 4 & 0 & 0 & 19 \\
\hline Mental Illness & 13 & 10 & 9 & 1 & 0 & 33 \\
\hline Hepatitis & 3 & 3 & 3 & 0 & 0 & 9 \\
\hline Infectious Diseases & 18 & 13 & 10 & 1 & 1 & 43 \\
\hline Eye Disease & 3 & 2 & 0 & 1 & 0 & 6 \\
\hline $\begin{array}{l}\text { Arthritis } \\
\text { osteoporosis }\end{array}$ & 11 & 2 & 3 & 0 & 0 & 16 \\
\hline Diabetes & 22 & 3 & 7 & 0 & 0 & 32 \\
\hline Epilepsy & 5 & 1 & 1 & 0 & 0 & 7 \\
\hline ENT & 8 & 1 & 4 & 0 & 0 & 13 \\
\hline Kidney & 8 & 1 & 1 & 0 & 0 & 10 \\
\hline Paralysis & 1 & 1 & 0 & 0 & 0 & 2 \\
\hline Thalassaemia & 2 & 1 & 0 & 0 & 0 & 3 \\
\hline HIV/AIDS & 11 & 2 & 2 & 0 & 0 & 15 \\
\hline Reproductive Related & 6 & 2 & 2 & 0 & 0 & 10 \\
\hline Digestive system & 7 & 2 & 1 & 0 & 0 & 10 \\
\hline Other Diseases & 6 & 2 & 2 & 0 & 0 & 10 \\
\hline Total & 142 & 55 & 50 & 3 & 1 & 251 \\
\hline
\end{tabular}

The remaining diseases coded in had the following frequencies: Arthritis and osteoporosis (16 articles, $1.86 \%)$, HIV/AIDS (15 Articles, 1.74\%), Heart Disease (13 Articles, 1.51\%), ENT (13Articles, 1.51\%). Following four Diseases, Reproductive Related, Digestive system, Kidney and 'other Diseases' were presented at (10 Articles, 1.16 $\%)$. Hepatitis (9 articles, 1.04\%), Epilepsy (7 Articles , .8\%), Eye Disease(6 Articles , .6\%), Thalassemia(3 Articles, $0.34 \%$ ) and Paralysis (2 articles, .23\%).

\subsection{Tone of Articles}

Framing, or second-level agenda-setting, is a process that can emphasize topics or use specific tones in order to sway the public (Entman, 1993). In health related news coverage, framing was justified by coding the tone in articles.

\begin{tabular}{lcccccc}
\hline Overall Tone of Article & \multicolumn{7}{c}{ Newspaper Id } & \multirow{2}{*}{ Total } \\
\cline { 3 - 6 } & Pakistan Times & Dawn & Daily Duniya & Daily Express & Nawai-e-Waqt & 230 \\
\cline { 1 - 6 } Positive & 34 & 35 & 107 & 24 & 30 & 130 \\
Negative & 48 & 18 & 32 & 11 & 21 & 94 \\
Mixed & 0 & 42 & 37 & 1 & 14 & 404 \\
Neutral & 99 & 72 & 129 & 46 & 123 & 858 \\
\hline Total & 181 & 167 & 305 & 82 & &
\end{tabular}

Table 4: Tone of Articles covered by The Newspapers

Almost half of total articles were found to be neutral in their tone (404 articles, 47.08\%). more than 1/4 (26.8\%) adopted a positive tone, while 130 articles (15.15\%) were coded as Negative in tone. Comparatively Less amount of Articles (94, 10.95\%) have mixed tone.

\section{Summary of Findings}

By presenting the theory leaden analysis of five Urdu and English newspaper of Pakistan, it has been explained the impact of news media in public perception on large scale. This research aimed to study health related issues in newspapers by analyzing the frequency of coverage of general health topics, risk factors, diseases and benefit factors. Secondly, framing theory postulated that choosing and excluding the information have tendency to strongly influence on the people. In this research, health related topics, tones, sources of information and the use of statistics are variables that help to better understand how health news is disseminated. This study has attempted to fill the gap in the field of literature by studying the newspapers samples for health news coverage in Pakistani perspective in the literature by studying the nature of coverage of health related news in Pakistan using newspaper samples. 
The salient purpose of the research has to make the content analysis of health related news coverage in newspapers named as Pakistan Times, Daily Dawn, Daily Express, Daily Duniya and Daily Nawai-e-Waqt from July , 2018 to June , 2019. The first goal was to determine how much attention health news articles received in the news to know about the health issues that are being addressed. All news articles on health in one-year period in five major newspapers of Pakistan are coded. An article on health issues has proven shorter than the average article in the newspaper, making the health of a less important presented in newspapers.

The next objective was to find the categories or types of health issues addressed. This is in terms of protected specialty topics, public health policy and scientific progress often covered. The coverage of certain diseases such as infectious diseases and mental illness is consistent with actual rates. However, some diseases such as diseases of the reproductive system and paralysis were underrepresented in news articles. Some risk factors, such as obesity, require greater coverage. This has serious consequences for public health as a every sixth man in Pakistan adults are facing obesity and every third one is facing overweight. Paying little attention on obesity in newspapers heighten unfamiliarity among people about this serious risk factor. With regard to the framing of news related to health topics, it was analyzed that maximum articles present certain aspects when discussing their own health issues in terms of reason, detection and remedies. News articles related to health were mostly covered in neutral and positive tone.

\section{References}

Abu Sabha, R., (1998). Effective Nutrition Education for Behaviour Change. Clarksville, MD: Wolf Rinke Associates, Inc.

Angell, M., \&Kassirer, J. P., (1994). Clinical research-What should the public believe? New England Journal of Medicine, 331,189-190.

Berry, T. R., Wharf-Higgins, J., \& Naylor, P. J., (2007). SARS wars An examination of the quantity and construction of health information in the news media. Health Communication, 21, 35-44.

Brodie, M., Hamel, E. C., Altman, D. E., Blendon, R. J., \& Benson, J. M. (2003). Health news and the American public, 1996-2002 Jour of Health Politics, Policy \& Law, 28(5), 927-951.

Buntin. M. B.. .lain, S. H., \& Blumenthal, D. (2010). Health information Technology: Laying the infrastructure for national health reform. Health affairs, 29(6), 1214 - 1219

Chang, C., (2012). News coverage of health-related issues and its impacts on perceptions. Journalists and health care professionals: what can we do about?

Clarke, J. N., \& Everest, M. M., (2006). Cancer in the mass print media: Fear, uncertainty and the medical model. Social Science \& Medicine, 62, 2591-2600.

Collins, P., Abelson, J., Pyman, H., \&Lavis, J., (2006). Are we expecting too much from print media? An analysis of newspaper coverage of the 2002 Canadian healthcare reform debate.Social Science \& Medicine, 63, 89-102.

Cooper, C.P., Yukimura, D., (2002). Science writers' reactions to a medical “ stoiy.SocSciMed 54, 1887-1896.

Covello, V. T., \& Peters, R. G., (2002). Women's perceptions of the risks of age-related diseases, including breast cancer: Reports from a 3-year research study. Health Communication, 14, 377-395.

Doak, C., Doak, L., Fredel, G., \& Meade, C., (1998).Improving comprehension for cancer patients with low literacy skills: Strategies for clinicians. CA: A Clinicians, 48, 151-162

Dutta-Bergman, M., (2004). Primary sources of health information: Comparisons in the domain of health attitudes, health cognitions, and health behaviors. Health Communication, 16, 273-278.

Gupta, A., and Sinha, A. K., (2010). 'Health Coverage in Mass Media: A Content Analysis', Journal of Communication, 1(1): 19-25.

Hale, J. L., Lemieux, R., \&Mongeau, P. A., (1995). Cognitive processing of fear-arousing message content. Communication Research, 22, 459-414.

Kahneman, D., Tversky, A., (1984).Choices, values, and frames Psychologist, Vol 39(4), 341-350. http://dx.doi.org/10.1037/0003-066X.39-4.341.

Kitzinger, J., (2004). Framing Abuse: Media Influence and Public Understanding of Sexual Violence against Children.

Luhmann, N., Cross, K., (2000). The Reality of the Mass: Stanford University Press

McCombs, M. E., \& Shaw, D. L., (1972).The agenda-setting function the press. Public Opinion Quarterly, 36,176 187. 
Patterson, C., Semple, S., Wood, K., Duffy, S., \& Hilton, S. (2015). A Quantitative Content Analysis of UK Newsprint Coverage of Proposed Legislation to Prohibit Smoking in Private Vehicles Carrying Children.Z/A/C Public Health, 15, 760. http://doi.org /I .1186/s12889-015-2110-x.

Schwitzer, G., Mudur, G., Henry, D., Wilson, A., Goozner, M., Simbra, M., Simbra, M., Sweet, M. \&Baverstock, K. A., (2005). What Are The Roles And Responsibilities of the Media in Disseminating Health Information? PLoS Med 2(8),321. doi: 10.1371/joumal.pmed.0020321.

Signorelli, N., (1993). Mass Media Images and Impact on Health: A Sourcebook. Westport, CT: Greenwood.

Tsfati, Y., Peri, Y., (2006). Mainstream media skepticism and exposure to sartorial and extranational news media: the case of Israel. Mass Communication Society. 9 (2), 165el 87. http://dx.d0i.0rg/1 0.1207/s1 5327825mcs0902_3

Wimmer, R.D., \& Dominick, J. R., (9th Ed) (201 1).Mass Media Research: An Introduction. Belmont CA: Wadsworth.

Witte, K., (1994). Fear control and danger control: A test of the extended parallel process model. Communication Monographs, 61, 113-134. 